\title{
Oxidation of 6-Methyl-2-phenylbenzofuran with Chromic Acid under Various Conditions. An Abnormal Dimeric Oxidation Product of the Benzofuran Derivative. Studies on the Heterocyclic Quinones. Vi)
}

\author{
Hisashi Ishir, Yoshimi Ishikawa, Keizo Mizukami, Hideki Mitsui, \\ and NisABURO IKEDA
}

Faculty of Pharmaceutical Sciences, Chiba University2)

(Received November 19, 1970)

\begin{abstract}
Oxidation of 6-methyl-2-phenylbenzofuran ${ }^{3)}$ with chromium trioxide in acetic acid gave an unusual dimeric oxidation product, $2,2^{\prime}$-dibenzoyloxy-4,4'-dimethylbenzil (II). Structural establishment came from several chemical evidences including an interesting acyl migration from 2,2'-dibenzoyloxy-4,4'-dimethylhydrobenzoin (III) to 2,2'-dimethoxy-4,4'-dimethylhydrobenzoin dibenzoate (IV) during methylation with diazomethane.

On the other hand, oxidation of the same benzofuran with Jones' reagent afforded 2-hydroxy-4-methylbenzil (IX). Furthermore, on treatment with chromium trioxide. pyridine complex, the material (II) was recovered quantitatively.
\end{abstract}

During a study of synthesis of heterocyclic quinone derivatives, we had occasion to examine the oxidation of 6-methyl-2-phenylbenzofuran ${ }^{3)}$ (I) with chromic acid and found the product of oxidation was to be depended upon a condition applied. In acetic acid, the benzofuran was abnormally oxidized to a dimeric product, but in sulfuric acid (Jones' reagent ${ }^{4)}$ ), to a different monomeric product. This paper deals with establishment of structures of the oxidation products under various conditions.

Tarbell, et al.,5) about twenty five years ago, reported 5- and 6-methylbenzo[b]thiophene gave the corresponding 4,7-quinones, when oxidized with chromic acid. We applied their condition to 6-methyl-2-phenylbenzofuran (I) and obtained colorless prisms, $\mathrm{mp} 174-175^{\circ}$, which have two carbonyl bands at $1740 \mathrm{~cm}^{-1}$ (a phenol benzoate) and at $1669 \mathrm{~cm}^{-1}$ (aconjugated ketone or aldehyde) in the infrared (IR) spectrum and have a sharp singlet due to an

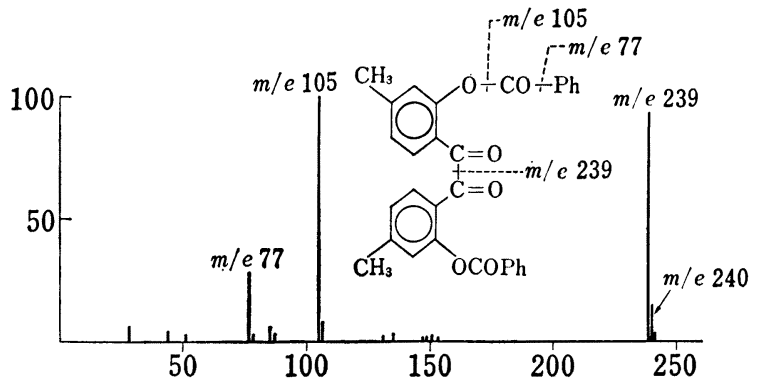

Fig. 1. Mass Spectrum of 2,2'-Dibenzoyloxy-4,4'dimethylbenzil (II) (Direct Inlet System) aryl methyl group or more at $7.67 \tau$ and multiplets due to aromatic protons between $3.12-2.17 \tau$ in the nuclear magnetic resonance (NMR) spectrum. As the product (II) shows only two maxima at $235 \mathrm{~m} \mu$ and $270 \mathrm{~m} \mu$ in the ultraviolet (UV) spectrum, the benzofuran ring of the starting material (I) was destroyed on the portion of a furan ring to give a simple benzenoid derivative. Since its NMR spectrum does not show any signal due to an aldehydic proton, it vigorously denied a structural assign-

1) Part IV: H. Ishii, M. Konno, M. Wakabayashi, F. Kuriyagawa, and N. Ikeda, Yakugaku Zasshi, 90, 1298 (1970).

2) Location: 1-33, Yayoi-cho, Chiba.

3) W. Davies and S. Middleton, J. Chem. Soc., 1958, 822; 1959, 3544.

4) K. Bowden, I.M. Heilbron, E.R.H. Jones, and B.C.L. idem, ibid., Weedon, J. Chem. Soc., $1946,39$.

5) D.S. Tarbell, D.K. Fukushima, and H. Dam, J. Am. Chem. Soc., 67, 1643 (1945); D.S. Tarbell and D.K. Fukushima, ibid., 68, 1456 (1946). 
ment of 2-benzoyloxy-4-methylbenzaldehyde $\left(\mathrm{C}_{15} \mathrm{H}_{12} \mathrm{O}_{3}\right)$, mol.wt. 240.25, which could be assumed by the presence of the peak of the highest mass at m/e 240 in its mass spectrum (Fig. 1). It was reasonable to assume that this material was an oxidation product of a dimer of the benzofuran (I), because the elementary analysis fits with the calculated value for the molecular formula $\mathrm{C}_{30} \mathrm{H}_{22} \mathrm{O}_{6}$ rather than $\mathrm{C}_{15} \mathrm{H}_{12} \mathrm{O}_{3}$.

The catalytic hydrogenation of the product (II) on palladium charcoal gave a hydroxybenzoate (III), 2,2'-dibenzoyloxy-4,4'-dimethylhydrobenzoin, as colorless needles, $\mathrm{mp} 149$ $150^{\circ}$, whose IR spectrum shows a hydroxy absorption at $3350 \mathrm{~cm}^{-1}$ and a carbonyl band at $1735 \mathrm{~cm}^{-1}$. In its NMR spectrum, there appeared new two signals, a $2 \mathrm{H} \operatorname{doublet}(J=2.5 \mathrm{cps})$ at $4.91 \tau$ and a $2 \mathrm{H}$ diffused singlet at $7.50 \tau$. Since, after addition of deuterium oxide, the former changed to a sharp singlet and the latter disappeared, these signals can be assigned to those of a secondary alcoholic group. As this product gave elementary analysis in agreement with the molecular formula $\mathrm{C}_{30} \mathrm{H}_{26} \mathrm{O}_{6}$, these observation could suggest that the two ketonic groups of the oxidation product (II) were reduced to the corresponding secondary alcoholic groups.

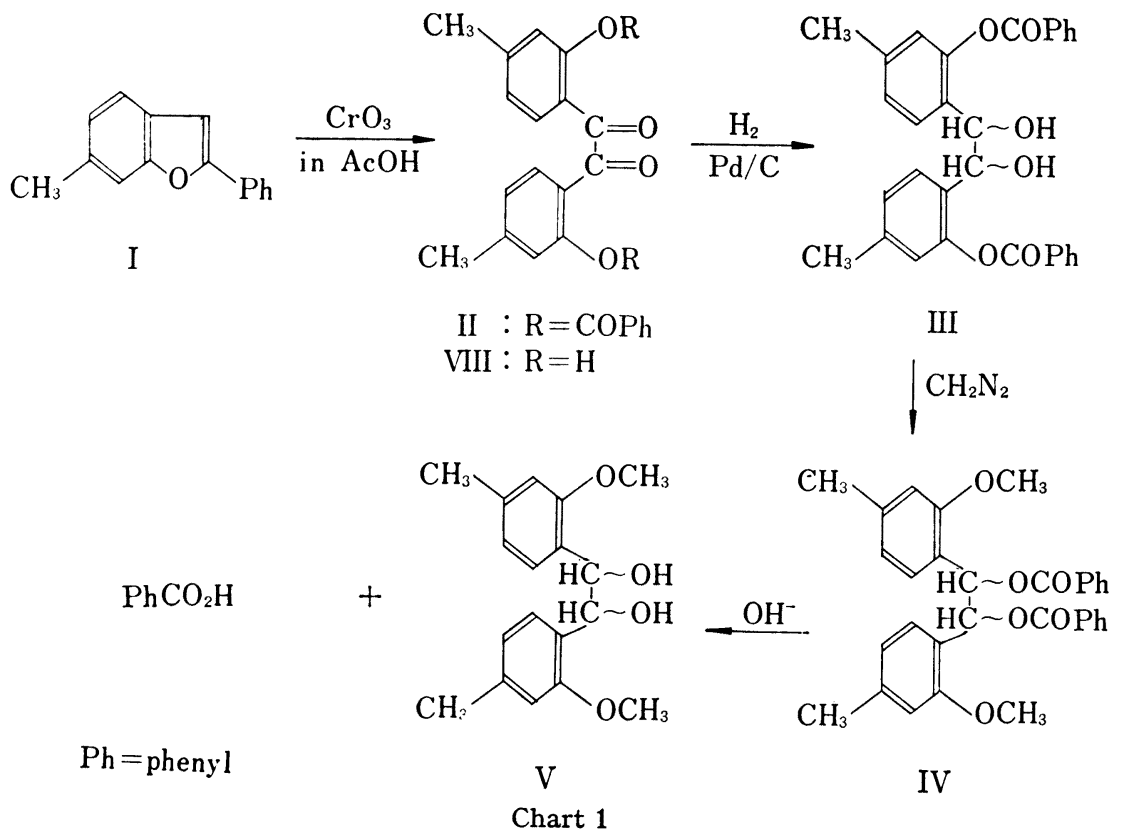

Treatment of the above hydroxybenzoate (III) with diazomethane gave a methoxybenzoate (IV) whose mass spectrum has the parent peak at $m / e 510$ corresponding to the molecular $\mathrm{C}_{32} \mathrm{H}_{30} \mathrm{O}_{6}$. It is noteworthy that, in the IR spectrum, the carbonyl band of the compound (IV) at $1710 \mathrm{~cm}^{-1}$ shifted to lower frequency region by $25 \mathrm{~cm}^{-1}$ than those of II and III. Furthermore, this compound (IV) could not have any secondary methoxy group, because there appeared no signal due to the proton situated on a carbon bearing a methoxy group above $3.51 \tau$. Consideration of these facts suggested the formal possibility that the methoxybenzoate (IV) might result from an intramolecular migration of a benzoyl group from a phenol group to a secondary alcohol. This assumption was supported by the following experiments.

Hydrolysis of the methoxybenzoate (IV) in a solution of $10 \%$ potassium hydroxide afforded benzoic acid and a neutral alcohol (V) whose IR spectrum shows a hydroxy band at $3520 \mathrm{~cm}^{-1}$ but no carbonyl absorption. In the NMR spectrum, this alcohol (V) shows a $2 \mathrm{H}$ doublet at $4.88 \tau(J=5 \mathrm{cps})$ and a $2 \mathrm{H}$ diffused doublet at $7.02 \tau$, which must be ascribed to the protons of secondary alcoholic groups, because, after addition of deuterium oxide, the former changed to a sharp singlet and the latter disappeared. Then, showing a $2 \mathrm{H}$ singlet 
at $3.37 \tau$ and a couple of $2 \mathrm{H}$ doublets $(J=8 \mathrm{cps})$ at 3.31 and $2.95 \tau$ in the aromatic proton region, the alcohol (V) must be a 1,2,4-trisubstituted benzene derivative. Conclusively, taking the presence of the parent peak at m/e 510 in the mass spectrum of methoxybenzoate (IV) into consideration, these facts led to a plausible structural assignment of this alcohol (V) to 2,2'-dimethoxy-4,4'-dimethylhydrobenzoin, which was consisted of the symmetrical two portions. The plausible explanation for the unusual methylation of the hydroxybenzoate (III) is the postulate that there is a direct equilibrium possible between a hydroxybenzoate (III) and an acyl migration product (IIIb) from a phenolic hydroxy group to an alcoholic hydroxy group in a solution. The intermediate state between these two hydroxy benzoate structures that would account for ease of such an acyl migration is the six-membered ortho acid form (IIIa) as shown in Chart 2. Consequently, the tentative process allows us the assignment of the oxidation product (II) to 2,2'-dibenzoyloxy-4,4'-dimethylbenzil.
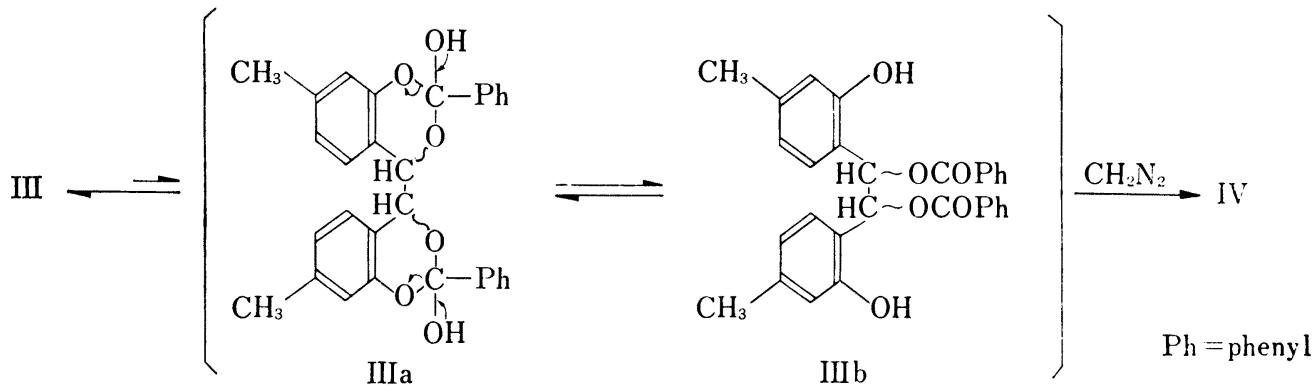

Chart 2

In order to confirm the dimeric structure of the oxidation product (II), several degradative reactions of the oxidation product (II) were undertaken. Oxidation of the product (II) with hydrogen peroxide in acetic acid followed by methylation with diazomethane afforded methyl 2-benzoyloxy-4-methylbenzoate (VI), $\mathrm{mp} 76-77^{\circ}$, which was confirmed by comparison with an authentic specimen prepared by benzoylation of $m$-cresotic acid (VII) followed by methylation. This evidence indicated the presence of an $\alpha$-diketone group in its molecule (Chart 3 ).

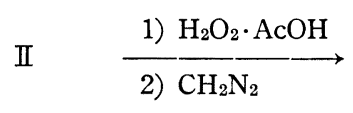<smiles>CCCOC(=O)c1cc(C)ccc1C</smiles>

$\mathrm{Ph}=$ phenyl Py $=$ pyridine
1) $\mathrm{PhCOCl} \cdot \mathrm{Py}$

2) $\mathrm{CH}_{2} \mathrm{~N}_{2}$

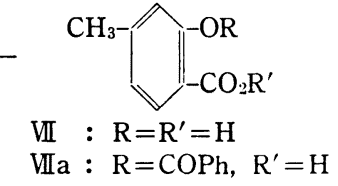

Chart 3

Then, hydrolysis of the oxidation product (II) with methoxide in methanol gave a mixture of benzoic acid and a yellow phenolic compound, 2,2'-dihydroxy-4,4'-dimethylbenzil (VII), mp 166-168 ${ }^{\circ}$, whose mass spectrum shows a parent's peak $(7 \%)$ at $m / e 270$ and a peak of $\mathrm{M}^{+} / 2$ at $m / e 135$ (base peak). This evidence allowed us to exclude the possibility that dimerization was happened at the stage of hydrogenation of the oxidation product (II) to the hydroxy benzoate (III). Consequently, we could establish that the oxidation product (II) is indeed 2,2' $2^{\prime}$-dibenzoyloxy-4,4'-dimethylbenzil. ${ }^{6}$ ) Formation of such a dimeric product by chromic oxidation is entirely new and suggests that, at the first stage, the benzofuran (I) dimerized?)

6) All synthetic approaches to this compound via benzoin or desoxybenzoin derivatives were unsuccessful.

7) The dimerization may be occurred through either the radical mechanism, that is, initiated by an abstraction of $\mathrm{C}_{3}$-hydrogen at first or the epoxidation followed by attacking of another benzofuran molecule. However, as a precise conclusion can not be easily obtained, we do not discuss the mechanism of formation of the dimer in this paper. 
at $\mathrm{C}_{3}$ position followed by further oxidation. Therefore, if the equivalent amount of chromic acid was used, the benzofuran could be oxidized to a dimer, 6,6'-dimethyl-2,2'-diphenyl-3,3' bibenzofuran. All efforts of these experiments were failed, but, on the way of the experiment, we occasionally found a fact that oxidation of the same benzofuran (I) with Jones' reagent ${ }^{4)}$ gave a different product (IX).

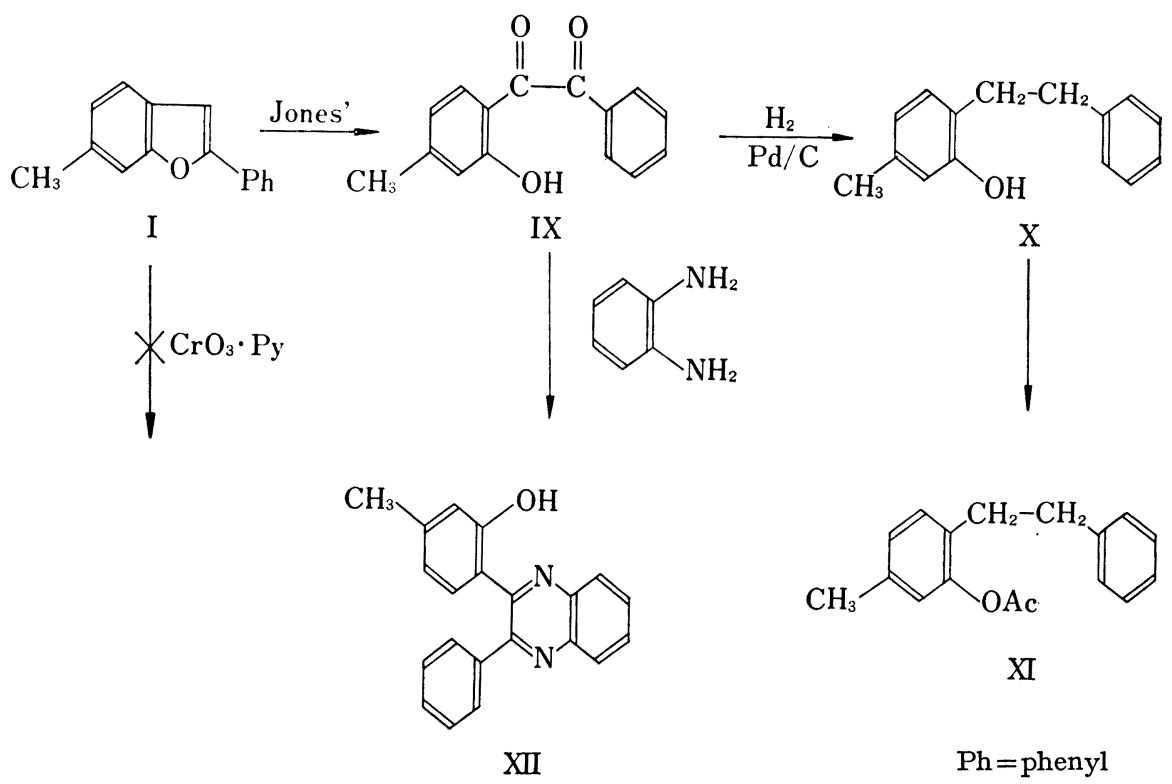

Chart 4

The oxidation product (IX) with Jones' reagent was obtained as yellow plates, $\mathrm{mp}$ 85$86^{\circ}, \mathrm{C}_{15} \mathrm{H}_{12} \mathrm{O}_{3}\left(\mathrm{M}^{+} \mathrm{m} / \mathrm{e} 240\right)$, whose IR spectrum shows a hydroxy band at $3050 \mathrm{~cm}^{-1}$ and a carbonyl band at $1690 \mathrm{~cm}^{-1}$. The mass spectrum of this compound (IX) gave a useful information on the presence of an $\alpha$-diketone group in its molecule which was suggested by characteristic yellow color. It shows two characteristic fragment ions $m / e$ 135 (base peak) and $m / e 105(56.5 \%)$, formation of which was reasonably explained by cleavage of the molecule at the center of an $\alpha$-diketone group. These observation allowed us the structural assign-

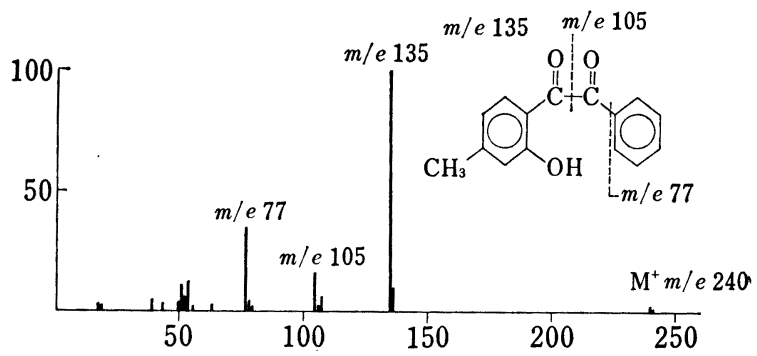

Fig. 2. Mass Spectrum of 2-Hydroxy-4-methylbenzil (IX) (Direct Inlet System) ment of this compound to 2-hydroxy-4-methylbenzil and this assignment was supported by the following evidences.

Hydrogenation of the compound (IX) on palladium charcoal gave a diphenylethan derivative (X), mp 62-63, whose IR spectrum shows a hydroxy band at $3540 \mathrm{~cm}^{-1}$ but no carbonyl band. In the NMR spectrum of this compound, there appeared a singlet at $7.21 \tau$ integrated for four protons. Such a signal was best assigned to those of benzylic methylenes produced by the reduction of benzoyl groups to benzyl. This observation was supported by the fact that its elementary analysis and mass spectrum shows the molecular formula, $\mathrm{C}_{15} \mathrm{H}_{16} \mathrm{O}\left(\mathrm{M}^{+}\right.$ 
$m / e$ 212). Treatment of this substance $(\mathrm{X})$ with acetic anhydride in pyridine afforded an oily acetate (XI) whose IR spectrum shows a carbonyl band at $1760 \mathrm{~cm}^{-1}$ due to a phenolic acetate group and no hydroxy. Its NMR spectrum shows a $3 \mathrm{H}$ singlet at $7.78 \tau$ due to an acetyl methyl group. From these spectral data, we could conclude the hydroxy group in the oxidation product (IX) should be originally situated as a phenolic group.

Treatment of the oxidation product (IX) with 0 -phenylenediamine gave 3-(4'-methyl-2'hydroxy)phenyl-2-phenylquinoxaline, $\mathrm{mp} 132-134^{\circ}$, which shows no carbonyl absorption in the IR spectrum and the parent peak at $m / e 312$ in the mass spectrum. Formation of this substance strongly supported the presence of an $\alpha$-diketone system in its molecule.

Final concern was the behavior of the benzofuran (I) on the treatment of it with chromium trioxide. pyridine complex which is the mildest condition among chromium salt oxidations. However, the starting material was recovered quantitatively in the reaction.

\section{Experimental ${ }^{8}$}

2,2'-Dibenzoyloxy-4,4'-dimethylbenzil (II)_-A solution of $4.33 \mathrm{~g}$ of chromic acid in $10 \mathrm{ml}$ of $80 \%$

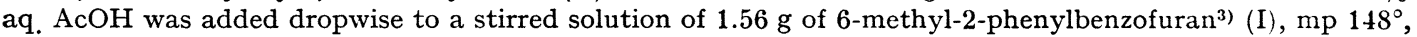
in $15 \mathrm{ml}$ of $\mathrm{AcOH}$. The reaction mixture was kept below $10^{\circ}$ during addition, then slowly brought to room temperature and allowed to stand for $20 \mathrm{hr}$. After decomposition of the excess of reagent with methanol, the mixture was concentrated in vacuo, diluted with water and extracted with ether. The extract was dried over $\mathrm{MgSO}_{4}$ and evaporated. The residue $(0.83 \mathrm{~g})$ in chloroform chromatographed on silicic acid and elution with chloroform gave crystals which were recrystallized from ethanol to give $0.49 \mathrm{~g}$ of colorless needles, mp 174-175 ${ }^{\circ}$. Anal. Calcd. for $\mathrm{C}_{30} \mathrm{H}_{22} \mathrm{O}_{6}: \mathrm{C}, 75.30 ; \mathrm{H}, 4.63$. Found: C, 75.24; H, 4.60. IR $v_{\max }^{\mathrm{CHCl}_{2}}\left(\mathrm{~cm}^{-1}\right)$ : 1740 (benzoate), $1669(\mathrm{C}=\mathrm{O})$. UV $\lambda_{\max }^{\mathrm{MoOH}} \mathrm{m} \mu(\log \varepsilon): 235$ (4.61), $270(4.37)$. NMR $\left(\mathrm{CDCl}_{3}\right) \tau: 7.67$ (6H, singlet, $\left.2 \times \mathrm{CH}_{3}\right), 3.12-2.17(16 \mathrm{H}$, multiplet, aromatic protons).

2,2'-Dibenzoyloxy-4,4'-dimethylhydrobenzoin (III)_-A mixture of $300 \mathrm{mg}$ of $2,2^{\prime}$-dibenzoyloxy-4,4'dimethylbenzil (II) and $900 \mathrm{mg}$ of $10 \% \mathrm{Pd}-\mathrm{C}$ in $20 \mathrm{ml}$ of ethyl acetoacetate was hydrogenated at room temperature under atomospheric pressure for $4 \mathrm{hr}$ and the catalyst was filtered off. The filtrate was evaporated to dryness in vacuo. The residue $(282 \mathrm{mg})$ was recrystallized from ether-cyclohexane to give $235 \mathrm{mg}$ of colorless needles, mp $149-150^{\circ}$. Anal. Calcd. for $\mathrm{C}_{30} \mathrm{H}_{26} \mathrm{O}_{6}: \mathrm{C}, 74.67 ; \mathrm{H}, 5.43$. Found: $\mathrm{C}, 74.46 ; \mathrm{H}$, 5.44. IR $v_{\max }^{\mathrm{Najol}}\left(\mathrm{cm}^{-1}\right): 3550(\mathrm{OH}), 1735(\mathrm{C}=\mathrm{O})$. $\quad \mathrm{NMR}\left(\mathrm{CDCl}_{3}\right) \tau: 7.71\left(6 \mathrm{H}\right.$, singlet, $\left.2 \times \mathrm{CH}_{3}\right), 7.50(2 \mathrm{H}$, diffused singlet, $2 \times \mathrm{OH}$, disappeared by addition of $\left.\mathrm{D}_{2} \mathrm{O}\right), 4.91(2 \mathrm{H}$, doublet, $J=2.5 \mathrm{cps}, 2 \times \mathrm{CHOH}$, changed to singlet by addition of $\left.\mathrm{D}_{2} \mathrm{O}\right), 3.17-1.94(16 \mathrm{H}$, multiplet, aromatic protons).

2,2'-Dimethoxy-4,4'-dimethylhydrobenzoin Dibenzoate (IV)_-To a solution of $210 \mathrm{mg}$ of $2,2^{\prime}$-dibenzoyloxy-4,4'-dimethylhydrobenzoin (III) in ether was added a solution of excess of diazomethane in ether. The solution was allowed to stand at room temperature for $48 \mathrm{hr}$. The solvent was removed under reduced pressure. The residue $(291.3 \mathrm{mg})$ in benzene was chromatographed on silicic acid and elution with benzene gave crystals which were recrystallized from benzene-cyclohexane to give $150 \mathrm{mg}$ of colorless needles, mp 211-212 ${ }^{\circ}$. Anal. Calcd. for $\mathrm{C}_{32} \mathrm{H}_{30} \mathrm{O}_{6}: \mathrm{C}, 75.27 ; \mathrm{H}, 5.92$. Found: C, 75.51; H, 5.85. IR $v_{\max }^{\text {Nujol }}\left(\mathrm{cm}^{-1}\right)$ : $1710(\mathrm{C}=\mathrm{O})$. $\mathrm{NMR}\left(\mathrm{CCl}_{4}\right) \tau: 7.72\left(6 \mathrm{H}\right.$, singlet, $\left.2 \times \mathrm{CH}_{3}\right), 6.36\left(6 \mathrm{H}\right.$, singlet, $\left.2 \times \mathrm{OCH}_{3}\right), 3.51-1.89(18 \mathrm{H}$, multiplet, aromatic protons and $2 \times \mathrm{CHOCOPh})$. Mass Spectrum $m / e: 510\left(\mathrm{M}^{+}\right), 255\left(\mathrm{M}^{+} / 2\right)$.

Hydrolysis of $2,2^{\prime}$-Dimethoxy $-4,4^{\prime}$-dimethylhydrobenzoin Dibenzoate (IV)—a) 2,2'-Dimethoxy-4,4'dimethylhydrobenzoin (V): A mixture of $100 \mathrm{mg}$ of $2,2^{\prime}$-dimethoxy-4,4'-dimethylhydrobenzoin dibenzoate (IV) and excess of $10 \%$ aq. $\mathrm{KOH}$ was refluxed for $30 \mathrm{~min}$. After dilution with water, the mixture was extracted with ether to separate a neutral fraction in ether and an acidic fraction in aqueous alkaline solution. The ethereal solution was dried over $\mathrm{MgSO}_{4}$ and evaporated. Recrystallization of the residue (53 mg) from chloroform-cyclohexane gave $38 \mathrm{mg}$ of colorless needles, mp 157-162 ${ }^{\circ}$ Anal. Calcd. for $\mathrm{C}_{18} \mathrm{H}_{22} \mathrm{O}_{4}:$ C, 71.50 ; $\mathrm{H}, 7.33$. Found: $\mathrm{C}, 71.57 ; \mathrm{H}, 7.07$. IR $\nu_{\max }^{\mathrm{Najol}}\left(\mathrm{cm}^{-1}\right): 3520(\mathrm{OH}) . \quad \mathrm{NMR}\left(\mathrm{CDCl}_{3}\right) \tau: 7.69(6 \mathrm{H}$, singlet, $\left.2 \times \mathrm{CH}_{3}\right), 7.02\left(2 \mathrm{H}\right.$, diffused doublet, $J=5 \mathrm{cps}, 2 \times \mathrm{OH}$, disappeared by addition of $\left.\mathrm{D}_{2} \mathrm{O}\right), 6.30(6 \mathrm{H}$, singlet, $\left.2 \times \mathrm{OCH}_{3}\right), 4.88\left(2 \mathrm{H}\right.$, doublet, $J=5 \mathrm{cps}$, changed to singlet by addition of $\left.\mathrm{D}_{2} \mathrm{O}, 2 \times \mathrm{CHOH}\right), 3.37$ ( $2 \mathrm{H}$, diffused singlet, $\mathrm{C}_{3}$ and $\left.\mathrm{C}_{3^{\prime}}-\mathrm{H}\right), 3.31\left(2 \mathrm{H}\right.$, diffused doublet, $J=8 \mathrm{cps}, \mathrm{C}_{5}$ and $\left.\mathrm{C}_{5^{\prime}}-\mathrm{H}\right), 2.95(2 \mathrm{H}$, doublet, $J=8 \mathrm{cps}$, $\mathrm{C}_{6}$ and $\left.\mathrm{C}_{6^{\prime}}-\mathrm{H}\right)$.

b) Benzoic Acid: The above aqueous alkaline solution made acidic with conc. $\mathrm{HCl}$ and extracted with ether. The extract was dried over $\mathrm{MgSO}_{4}$ and evaporated. Recrystallization of the residue from

8) All melting points were observed on a microscopic hot stage and are uncorrected. All NMR spectra were obtained with tetramethylsilane as an internal standard on a JOEL's JNM-4H-100 NMR spectrometer $(100 \mathrm{Mc})$. For column chromatography, silicic acid, 100 mesh Mallinckrodt Chemical Works, was used. 
hexane gave $51 \mathrm{mg}$ of colorless feathers, mp $122-126^{\circ}$, which were identified with the authentic sample of benzoic acid by comparison of IR spectra and a mixed melting point determination.

Oxidation of 2,2'-Dibenzoyloxy-4,4'-dimethylbenzil (II) with Hydrogen Peroxide [Methyl 2-Benzoyloxy4-methylbenzoate (VI)]—To a solution of $200 \mathrm{mg}$ of $2,2^{\prime}$-dibenzoyloxy-4,4'-dimethylbenzil (II) in $8 \mathrm{ml}$ of $\mathrm{AcOH}$ was added dropwise $14 \mathrm{ml}$ of hydrogen peroxide under reflux. The mixture was heated for $3 \mathrm{hr}$ and cooled to room temperature. After addition of a small amount of $\mathrm{MnO}_{2}$, the mixture was allowed to stand at room temperature overnight, filtered, diluted with water and extracted with ether. The extract was dried over $\mathrm{MgSO}_{4}$ and evaporated to dryness in vacuo. All efforts to crystallization of the residue were failed. Then, a solution of excess of diazomethane in ether was added to a solution of the residue in ether. The mixture was allowed to stand at room temperature for $48 \mathrm{hr}$ and evaporated to dryness in vacuo. The residue $(153 \mathrm{mg})$ in benzene chromatographed on silicic acid. Elution with benzene was followed by TLC and separated into two fractions. The first fraction gave $7 \mathrm{mg}$ of colorless oil which was identified with a sample of methyl benzoate on TLC and by comparison of IR spectra. The second fraction afforded a solid mass which was recrystallized from hexane to give colorless plates, mp 76-77 . Anal. Calcd. for $\mathrm{C}_{16} \mathrm{H}_{14} \mathrm{O}_{4}$ : $\mathrm{C}, 71.10 ; \mathrm{H}, 5.22$. Found: $\mathrm{C}, 71.55 ; \mathrm{H}, 5.34 . \quad$ IR $\nu_{\max }^{\text {Nujol }}\left(\mathrm{cm}^{-1}\right): 1720(\mathrm{C}=\mathrm{O}) . \mathrm{NMR}\left(\mathrm{CCl}_{4}\right) \tau: 7.57(3 \mathrm{H}$, singlet, $\left.\mathrm{CH}_{3}\right), 6.35\left(3 \mathrm{H}\right.$, singlet, $\left.\mathrm{OCH}_{3}\right), 3.02\left(1 \mathrm{H}\right.$, diffused singlet, $\left.\mathrm{C}_{3}-\mathrm{H}\right), 2.91\left(1 \mathrm{H}\right.$, diffused doublet, $\left.J=8 \mathrm{cps}, \mathrm{C}_{5}-\mathrm{H}\right)$, $2.65-2.40\left(3 \mathrm{H}\right.$, multiplet, aromatic protons), $2.08\left(1 \mathrm{H}\right.$, doublet, $\left.J=8 \mathrm{cps}, \mathrm{C}_{6}-\mathrm{H}\right), 1.90-1.73$ (2H, multiplet, aromatic protons). Mass Spectrum $m / e: 270\left(\mathrm{M}^{+}\right)$. This compound was identified with the sample prepared by the alternative route by comparison of IR spectra and mixed melting point.

Authentic Methyl 2-Benzoyloxy-4-methylbenzoate-a) 2-Benzoyloxy-4-methylbenzoic Acid (VIIa): To a solution of $1.00 \mathrm{~g}$ of $m$-cresotic acid (VII), 2-hydroxy-4-methylbenzoic acid and $1 \mathrm{ml}$ of pyridine in $5 \mathrm{ml}$ of ether was added dropwise $0.97 \mathrm{~g}$ of benzoyl chloride. The mixture was kept below $5^{\circ}$ during the addition, then slowly brought to room temperature and allowed to stand overnight. The solution was poured into a mixture of $5 \mathrm{ml}$ of conc. $\mathrm{HCl}$ and $5 \mathrm{~g}$ of ice, and extracted with ether. The extract was washed with $5 \%$ $\mathrm{HCl}$ and $5 \% \mathrm{NaHCO}_{3}$, dried over $\mathrm{MgSO}_{4}$ and evaporated. Recrystallization of the residue from ether-hexane gave $1.32 \mathrm{~g}$ of colorless needles, $\mathrm{mp} 177-179^{\circ}$. Anal. Calcd. for $\mathrm{C}_{15} \mathrm{H}_{12} \mathrm{O}_{4} ; \mathrm{C}, 70.30 ; \mathrm{H}, 4.72$. Found: $\mathrm{C}$, $70.21 ; \mathrm{H}, 4.65$. IR $\nu_{\max }^{\text {Nafol }}\left(\mathrm{cm}^{-1}\right): 3000-2500(\mathrm{COOH}), 1735(\mathrm{C}=\mathrm{O}), 1685(\mathrm{C}=\mathrm{O})$. NMR $\left(\mathrm{CDCl}_{3}\right) \tau: 7.60$ $\left(3 \mathrm{H}\right.$, singlet, $\left.\mathrm{CH}_{3}\right), 2.96\left(1 \mathrm{H}\right.$, singlet, $\left.\mathrm{C}_{3}-\mathrm{H}\right), 2.87\left(1 \mathrm{H}\right.$, doublet, $\left.J=8 \mathrm{cps}, \mathrm{C}_{5}-\mathrm{H}\right), 2.30-2.68(3 \mathrm{H}$, multiplet, aromatic protons), $2.02\left(1 \mathrm{H}\right.$, doublet, $\left.J=8 \mathrm{cps}, \mathrm{C}_{6}-\mathrm{H}\right), 1.77-1.92(2 \mathrm{H}$, multiplet, aromatic protons $),-0.60$ $(1 \mathrm{H}$, broad singlet, $\mathrm{COOH})$. Mass Spectrum $m / e: 256\left(\mathrm{M}^{+}\right)$.

b) Methyl 2-Benzoyloxy-4-methylbenzoate (VI): To a solution of $500 \mathrm{mg}$ of 2-benzoyloxy-4-methylbenzoic acid (VIIa) in $120 \mathrm{ml}$ of ether was added a solution of diazomethane in ether. After decomposition of excess of diazomethane with acetic acid, the solution was washed with $5 \% \mathrm{NaHCO}_{3}$, dried over $\mathrm{MgSO}_{4}$ and evaporated. The residue $(510 \mathrm{mg})$ in cyclohexane was chromatographed on silicic acid, elution with benzene gave $380 \mathrm{mg}$ of colorless needles, $\mathrm{mp} 76-77^{\circ}$, which were recrystallized from hexane.

Hydrolysis of 2,2'-Dibenzoyloxy-4,4'-dimethylbenzil (II)-a) 2,2'-Dihydroxy-4,4'-dimethylbenzil (VIII): A solution of $300 \mathrm{mg}$ of $2,2^{\prime}$-dibenzoyloxy-4,4'-dimethylbenzil (II) in $10 \mathrm{ml}$ of methanol containing of $300 \mathrm{mg}$ of metal sodium was refluxed for $1.2 \mathrm{hr}$ and evaporated to dryness in vacuo. The residue was dissolved in water and extracted with ether. The ethereal solution was dried over $\mathrm{MgSO}_{4}$ and evaporated. The residue in benzene was chromatographed on silicic acid. Elution with benzene gave $35 \mathrm{mg}$ of yellow needles, $\mathrm{mp} 166-168^{\circ}$, which were recrystallized from hexane. Anal. Calcd. for $\mathrm{C}_{16} \mathrm{H}_{14} \mathrm{O}_{4}: \mathrm{C}, 71.10 ; \mathrm{H}, 5.22$. Found: C, 70.88; H, 5.53. IR $\nu_{\max }^{\text {Najol }}\left(\mathrm{cm}^{-1}\right): 1630(\mathrm{C}=\mathrm{O}) . \quad \mathrm{UV} \lambda_{\max }^{\mathrm{EtOH}} \mathrm{m} \mu(\log \varepsilon): 268(4.18), 335(3.94)$. NMR $\left(\mathrm{CDCl}_{3}\right) \tau: 7.66\left(6 \mathrm{H}\right.$, singlet, $\left.2 \times \mathrm{CH}_{3}\right), 3.33\left(2 \mathrm{H}\right.$, diffused doublet, $J=8 \mathrm{cps}, \mathrm{C}_{5}$ and $\left.\mathrm{C}_{5}-\mathrm{H}\right), 3.15(2 \mathrm{H}$, diffused singlet, $\mathrm{C}_{3}$ and $\left.\mathrm{C}_{3^{\prime}}-\mathrm{H}\right), 2.70\left(2 \mathrm{H}\right.$, doublet, $J=8 \mathrm{cps}, \mathrm{C}_{6}$ and $\left.\mathrm{C}_{6}-\mathrm{H}\right),-1.28(2 \mathrm{H}$, singlet, $2 \times \mathrm{OH}$, disappeared by addition of $\left.\mathrm{D}_{2} \mathrm{O}\right)$. Mass Spectrum $m / e: 270\left(\mathrm{M}^{+}\right), 135\left(\mathrm{M}^{+} / 2\right)$.

b) Benzoic Acid: The alkaline mother liquor containing an acidic product was made acidic with conc. $\mathrm{HCl}$ and extracted with ether. The extract was dried over $\mathrm{MgSO}_{4}$ and evaporated to dryness. Recrystallization of the residue from hexane afforded $83 \mathrm{mg}$ of benzoic acid, $\mathrm{mp} 119-125^{\circ}$, as colorless feathers which was identified with a sample of benzoic acid by comparison of IR spectra and the mixed melting point determination.

Oxidation of 6-Methyl-2-phenylbenzofuran (I) with Jones' Reagent [2-Hydroxy-4-methylbenzil (IX)] To a solution of $100 \mathrm{mg}$ of 6-methyl-2-phenylbenzofuran (I) in $40 \mathrm{ml}$ of acetone was added dropwise $4 \mathrm{ml}$ of Jones' reagent $t^{4}$ at $5^{\circ}$. After addition of the reagent, the mixture was brought to room temperature and allowed to stand for $30 \mathrm{~min}$ with stirring. The excess of reagent was destroyed by methanol and the mixture was evaporated to dryness in vacuo. The residue was dissolved in water and extracted with ether. The extract was dried over $\mathrm{MgSO}_{4}$ and evaporated. The residue in benzene was chromatographed on silicic acid and the first part of elution with benzene was separated from the other fraction. TLC showed the former fraction containing a main product but still contaminated with a small amount of by-product. The fraction was dissolved in benzene again and chromatographed on $\mathrm{Al}_{2} \mathrm{O}_{3}$ (Woelm, neutral, grade I). After removal of top elution containing a by-product $(7 \mathrm{mg})$, following elution gave $30 \mathrm{mg}$ of yellow plates, $\mathrm{mp} 85-86^{\circ}$, which were recrystallized from hexane. Anal. Calcd. for $\mathrm{C}_{15} \mathrm{H}_{12} \mathrm{O}_{3}: \mathrm{C}, 74.99 ; \mathrm{H}, 5.03$. Found: C, 75.16; $\mathrm{H}$, 4.99. IR $\nu_{\max }^{\mathrm{NnJOl}}\left(\mathrm{cm}^{-1}\right): 3050(\mathrm{OH}), 1690(\mathrm{C}=\mathrm{O})$. UV $\lambda_{\max }^{\mathrm{EtOH}} \mathrm{m} \mu(\log \varepsilon): 210(4.39), 264(4.18), 336(3.68)$. NMR $\left(\mathrm{CCl}_{4}\right) \tau: 7.65\left(3 \mathrm{H}\right.$, singlet, $\left.\mathrm{CH}_{3}\right), 3.40\left(1 \mathrm{H}\right.$, diffused doublet, $\left.J=8 \mathrm{cps}, \mathrm{C}_{5}-\mathrm{H}\right), 3.19(1 \mathrm{H}$, diffused singlet, 
$\left.\mathrm{C}_{3}-\mathrm{H}\right), 2.71\left(1 \mathrm{H}\right.$, doublet, $\left.J=8 \mathrm{cps}, \mathrm{C}_{6}-\mathrm{H}\right), 2.63-2.00(5 \mathrm{H}$, multiplet, aromatic protons $),-0.95(1 \mathrm{H}$, singlet, $\mathrm{OH}$, disappeared by addition of $\left.\mathrm{D}_{2} \mathrm{O}\right)$. Mass Spectrum $m / e: 240\left(\mathrm{M}^{+}\right)$.

5-Methyl-2-phenethylphenol (X)_-A mixture of $100 \mathrm{mg}$ of 2-hydroxy-4-methylbenzil (IX) and $300 \mathrm{mg}$ of $10 \% \mathrm{Pd}-\mathrm{C}$ in $20 \mathrm{ml}$ of ethanol was hydrogenated at room temperature under atmospheric pressure until no more hydrogen was absorbed and the catalyst was filtered off. The filtrate ${ }^{9)}$ was evaporated to dryness in vacuo. Recrystallization of the residue $(74 \mathrm{mg})$ from hexane gave $66 \mathrm{mg}$ of colorless plates, $\mathrm{mp} 62-63^{\circ}$. $\mathrm{FeCl}_{3}$ test positive. Anal. Calcd. for $\mathrm{C}_{15} \mathrm{H}_{16} \mathrm{O}: \mathrm{C}, 84.87 ; \mathrm{H}, 7.60$. Found: $\mathrm{C}, 85.02 ; \mathrm{H}, 7.68$. IR $\nu_{\mathrm{max}}^{\mathrm{NuJj}}\left(\mathrm{cm}^{-1}\right)$ : $3540(\mathrm{OH})$. UV $\lambda_{\max }^{\mathrm{stoH}} \mathrm{m} \mu(\log \varepsilon): 210(4.31), 278(3.45) . \quad \mathrm{NMR}\left(\mathrm{CCl}_{4}\right) \tau: 7.79\left(3 \mathrm{H}\right.$, singlet, $\left.\mathrm{CH}_{3}\right), 7.21(4 \mathrm{H}$, singlet, $\left.\mathrm{ArCH}_{2} \mathrm{CH}_{2} \mathrm{Ph}\right), 5.86\left(1 \mathrm{H}\right.$, singlet, $\mathrm{OH}$, disappeared by addition of $\left.\mathrm{D}_{2} \mathrm{O}\right), 3.61(1 \mathrm{H}$, diffused singlet, $\left.\mathrm{C}_{6}-\mathrm{H}\right), 3.49\left(1 \mathrm{H}\right.$, diffused doublet, $\left.J=8 \mathrm{cps}, \mathrm{C}_{4}-\mathrm{H}\right), 3.18\left(1 \mathrm{H}\right.$, doublet, $\left.J=8 \mathrm{cps}, \mathrm{C}_{3}-\mathrm{H}\right), 2.89(5 \mathrm{H}$, diffused singlet, aromatic protons). Mass Spectrum $m / e$ : $212\left(\mathrm{M}^{+}\right)$.

3-Acetoxy-4-phenethyltoluene (XI)_-A solution of $60 \mathrm{mg}$ of 5-methyl-2-phenethylphenol (X) in $1.5 \mathrm{ml}$ of pyridine and $1.5 \mathrm{ml}$ of acetic anhydride was allowed to stand overnight at room temperature. The solution was poured into ice-water and extracted with ether. The ethereal solution was washed with a $5 \% \mathrm{HCl}$, dried over $\mathrm{MgSO}_{4}$ and evaporated to dryness in vacuo. Distillation of the residue, bp $101-102^{\circ}(0.5 \mathrm{mmHg})$ gave $54 \mathrm{mg}$ of colorless oil. Anal. Calcd. for $\mathrm{C}_{17} \mathrm{H}_{18} \mathrm{O}_{2}: \mathrm{C}, 80.28 ; \mathrm{H}, 7.13$. Found: C, 80.35; $\mathrm{H}, 7.27$. IR $\nu{\underset{m a x}{\mathrm{Fim}}}_{\mathrm{Fim}}\left(\mathrm{cm}^{-1}\right): 1760(\mathrm{C}=\mathrm{O}), 1200(\mathrm{C}-\mathrm{O}) . \quad \mathrm{NMR}\left(\mathrm{CCl}_{4}\right) \tau: 7.78\left(3 \mathrm{H}\right.$, singlt, $\left.\mathrm{CH}_{3}\right), 7.69\left(3 \mathrm{H}\right.$, singlet, $\left.\mathrm{CH}_{3}\right), 7.27$ $\left(4 \mathrm{H}\right.$, singlet, $\left.\mathrm{ArCH}_{2} \mathrm{CH}_{2} \mathrm{Ph}\right), 3.23\left(1 \mathrm{H}\right.$, diffused singlet, $\left.\mathrm{C}_{2}-\mathrm{H}\right), 3.13-2.78(7 \mathrm{H}$, multiplet, aromatic protons). Mass Spectrum $m / e: 254\left(\mathrm{M}^{+}\right)$.

3-(4'-Methyl-2'-hydroxyphenyl)-2-phenylquinoxaline (XII)_-A mixture of $50 \mathrm{mg}$ of 2-hydroxy-4-methylbenzil (IX) and $22.7 \mathrm{mg}$ of $o$-phenylenediamine in $5 \mathrm{ml}$ of acetic acid was refluxed for $45 \mathrm{~min}$, cooled, diluted with water, and ice-cooled. The yellow crystals precipitated $(71.8 \mathrm{mg})$ were filtered and recrystallized from ethanol to give $48 \mathrm{mg}$ of orange prisms, mp 132-134 ${ }^{\circ}$. Anal. Calcd. for $\mathrm{C}_{21} \mathrm{H}_{16} \mathrm{ON}_{2}: \mathrm{C}, 80.75 ; \mathrm{H}, 5.16$. Found: $\mathrm{C}, 80.86 ; \mathrm{H}, 5.22$. NMR $\left(\mathrm{CCl}_{4}\right) \tau: 7.72\left(3 \mathrm{H}\right.$, singlet, $\left.\mathrm{CH}_{3}\right), 3.74\left(1 \mathrm{H}\right.$, diffused doublet, $\left.J=8 \mathrm{cps}, \mathrm{C}_{5}-\mathrm{H}\right)$, $3.20\left(1 \mathrm{H}\right.$, diffused singlet, $\left.\mathrm{C}_{3^{\prime}}-\mathrm{H}\right), 3.16\left(1 \mathrm{H}\right.$, doublet, $\left.J=8 \mathrm{cps}, \mathrm{C}_{6^{\prime}}-\mathrm{H}\right), 2.70-2.53(3 \mathrm{H}$, multiplet, aromatic protons), $2.50-2.20(4 \mathrm{H}$, multiplet, aromatic protons $), 2.10-1.85(2 \mathrm{H}$, multiplet, aromatic protons $),-1.90$ $\left(1 \mathrm{H}\right.$, singlet, $\mathrm{OH}$, disappeared by addition of $\left.\mathrm{D}_{2} \mathrm{O}\right)$. Mass Spectrum m/e: $312\left(\mathrm{M}^{+}\right)$.

Acknowledgement The authors are grateful to Prof. K. Miyaki, Director of the institute of Food Microbiology, Chiba University, for his heartful encouragement. Thanks are also due to Mr. S. Tanaka, Mr. T. Hirose and the members of the analytical center of Eisai Co., Ltd. for elementary analysis and to Miss F. Kuriyagawa and Miss Y. Tomura, Chiba University, for NMR and Mass Spectra measurements.

9) We could not find any evidence for formation of 2-hydroxy-4-methylhydrobenzoin even on TLC. 